\title{
Rapid Determination of Boron in 61 Soil, Sediment, and Rock Reference Materials by ICP-MS
}

\author{
Ting Liu ${ }^{\mathrm{a}, \mathrm{b}}$, Tao $\mathrm{He}^{\mathrm{a}}$, Quanhui Shi ${ }^{\mathrm{a}}$, and Qian $\mathrm{Ni}^{*}$,a,b \\ a State Key Laboratory of Biogeology and Environmental Geology, \\ China University of Geosciences, Wuhan 430074, P.R. China \\ b State Key Laboratory of Geological Processes and Mineral Resources, \\ China University of Geosciences, Wuhan 430074, P.R. China
}

\section{INTRODUCTION}

Boron in soils and sediments is essential to plant growth and crop yields (1). Deficient and excessive concentrations of B occur frequently, resulting in failure to meet internal growth needs and causing toxicity to the plants, respectively (2).

Hence, chemical analysis of soils and sediments is valuable for monitoring the level of B to properly manage the environment (2). Besides, the fluid-mobile element B and its isotopes are efficient tracers of fluid-related processes. In the subduction zone processes, B and its isotopes were reported to define the link between subduction input and arc output (3-7). For terrestrial borate ore deposits, B as an indicator element was applied to investigate the relationship of its anomalies to completely delineate ore bodies by a soil geochemical study (8). Therefore, there is an urgent need for the accurate determination of the boron content in soil, sediment, and rock samples.

Several plasma-based techniques, including inductively coupled plasma optical emission spectrometry (ICP-OES) and ICP mass spectrometry (ICP-MS) $(9,10)$, are commonly applied to determine the boron concentration in aqueous and solid samples $(8,11)$. ICP-OES detects $B$ wavelengths typically monitored at $249.678 \mathrm{~nm}$ and $249.773 \mathrm{~nm}$, which are near the wavelength of iron (9). If the sample has a high iron concentration, boron determination by ICP-OES is

\footnotetext{
*Corresponding autbor.

E-mail: niq1981@163.com

Tel.: +862767883452

Fax: +862767883456
}

\section{ABSTRACT}

Boron (B) is an important geochemical tracer for environmental and geological studies. This study presents a rapid acid digestion method with ammonia dilution to detect boron in soil, sediment, and rock samples using inductively coupled plasma mass spectrometry (ICP-MS). It took only 30 minutes of digestion time to completely recover $B$ in $50 \mathrm{mg}$ of soil (GSS-7), sediment (GSD-18), and rock (GSR-2) reference materials at a high digestion temperature of $190{ }^{\circ} \mathrm{C}$ using $1 \mathrm{~mL} \mathrm{HNO}_{3}$ and $1 \mathrm{~mL} \mathrm{HF}$ in a PTFE-lined stainlesssteel bomb. No loss of B was found at a digestion temperature of $190^{\circ} \mathrm{C}$ for 30 hours. The wellknown memory effect of $B$ was eliminated by using an ammonia dilution method. Moreover, the alkaline sample solutions created by ammonia dilution also avoided the corrosiveness of HF in the ICP-MS sample introduction system. Rhodium is a more suitable internal standard element than In and $\mathrm{Y}$ in the alkaline medium. Compared to the standard sample cone $+\mathrm{H}$ skimmer cone $(\mathrm{S}+\mathrm{H}$ cone), the standard sample cone $+\mathrm{X}$ skimmer cone $(\mathrm{S}+\mathrm{X}$ cone $)$ increases the sensitivity of $\mathrm{B}$ by a factor of 7.0-8.2 in ICP-MS. The proposed method was successfully applied for the rapid determination of B in soil, sediment, and rock reference materials.
\end{abstract}

affected by iron interference (9). Compared to ICP-OES, ICP-MS has been developed for the rapid determination of ultra-trace elements, including $\mathrm{B}$, because of its higher sensitivity and reduced interference (12-17).
Precise and accurate determination of B in various solid samples by ICP-MS and ICP-OES requires complete extraction of $B$ from the sample. Solid samples, especially rocks, require extraction of boron using alkali fusion, pyro-hydrolysis, or acid dissolution $(18,19)$. Generally, dissolution carried out by alkali fusion with fluxes, such as sodium carbonate (flux: rock 8:1) or sodium hydroxide $(5: 1)$ in a $\mathrm{Pt}$ or $\mathrm{Ni}$ crucible at $900-1500{ }^{\circ} \mathrm{C}$, is an effective technique for relatively large samples (18-20). A 4:1 mixture of sodium carbonate and divalent cation oxides (e.g., $\mathrm{ZnO}$ ) was suggested for the destruction of solid samples prior to analysis of volatile elements such as B (21). The major disadvantage of the technique is that less than $90 \%$ of total boron in the sample is extracted (18). However, pyro-hydrolysis separation of $B$ is a successful method and does not require sample decomposition (9). Michel et al. (22) proposed a modified pyrohydrolysis technique to fix the problem of high blank contribution and an incomplete $B$ recovery from samples of low concentration. However, the issue remains that cleaning the pyro-hydrolysis apparatus is difficult (18); therefore, this technique is unsuitable for large batches of samples. Additionally, use of acid digestion (e.g., HF and $\mathrm{HNO}_{3}$ ) for the extraction of $\mathrm{B}$ from solids other than biogenic carbonates is complicated (23), mainly because B volatilizes with HF (9). In order to effectively avoid the loss of B volatilization, Hlaváček et al. (24) found that phosphoric acid in a sample solution reduces the volatility of boric acid with water vapor. Ishikawa and Nakamura $(25,26)$ reported that the loss of boron 
volatilization was avoided by using $\mathrm{HF}$ and $\mathrm{HCl}$ in the presence of mannitol because of the formation of a boron-mannitol complex. The method of mannitol plus HF to avoid boron loss has been widely used (27-30). Wei et al. (28) placed a mixture of $100 \mathrm{mg}$ rock powder, $100 \mathrm{~mL} \mathrm{H}_{2} \mathrm{O}_{2}, 1 \mathrm{~mL} \mathrm{HF}$, and $100 \mathrm{~mL}$ mannitol on a hot plate at a temperature of $60{ }^{\circ} \mathrm{C}$ for three days in the acid digestion process and the rock powder was dissolved. In particular, Gaillardet et al. (31) found that no loss of boric acid occurred when $1 \mu \mathrm{g}$ of B was evaporated in water, $\mathrm{HCl}, \mathrm{HF}$, and acetone solutions at $60-65^{\circ} \mathrm{C}$; however, boron was highly volatile when the dried residue of the evaporation was heated further. After these evaporation tests $(31,32)$, it was found that mannitol did not completely suppress B volatilization, particularly when the evaporation process was continued through dryness.

Admittedly, ICP-MS has some problems when measuring boron, including the resultant high memory effect. The boron memory effect originates from the tendency of boron to volatilize as boric acid from the sample solution layer that covers the inside surface of the spray chamber (33), resulting in a cross-contamination effect. In addition, B has a bad washout behavior. Sun et al. (34) found that dilute nitric acid did not reduce the $B$ signals to blank levels with a 10-minute washout after $100 \mathrm{ng} \mathrm{mL}^{-1} \mathrm{~B}$ was introduced over a period of $5 \mathrm{~min}$ utes. Some efforts have been made to eliminate or minimize the memory effect, including different washing solutions (e.g., sodium fluoride, mannitol, ammonia solution, and ammonia gas) (33-36). Al-Ammar et al. (33) indicated that only a 20-second washout was required to completely eliminate the boron memory effect and reduce boron signals to blank levels by injecting a small volume of ammonia solution into the spray chamber simultaneously with the sample solution. Al-Ammar et al. (35) also noted that introduction of ammonia gas into the spray chamber within 2 minutes of washing efficiently removed the boron memory effect. In recent studies, practical applications have been reported $(37,38)$. In contrast to these studies, Vogl et al. (39) reported that the memory effect of B was minimized by washing with dilute $\mathrm{HCl}$ for 5.5 minutes, and matching the medium of all solutions for ICP-MS measurement without any additives.

This study presents a rapid closed-vessel acid digestion method for the ICP-MS determination of B in soil, sediment, and rock reference materials. Experimental digestion products before ICP-MS analysis were changed to alkaline medium by ammonia dilution. It should be noted that this method does not involve any sample evaporation or drying processes, thereby avoiding the loss of B volatilization. The analysis was focused on the effect of digestion time, ammonia matrix, different cone combinations, selection of internal standard elements, and the memory effect on B measurement. The method was also used successfully to detect B in 61 soil, sediment, and rock reference materials.

\section{EXPERIMENTAL}

\section{Instrumentation and Data Acquisition}

Experimental digestion products were analyzed using an Element XR sector field ICP-MS instrument (Thermo Fisher Scientific, Bremen, Germany) at the State Key Laboratory of Geological Processes and Mineral Resources, University of Geosciences in Wuhan, P.R. China. The high abundance isotope ${ }^{11} \mathrm{~B}$ (80.1\%) was utilized. The low abundance isotope of ${ }^{10} \mathrm{~B}$ (19.9\%) was not selected because of spectral overlap interference from ${ }^{20} \mathrm{Ne}^{2+}$ and ${ }^{40} \mathrm{Ar}^{4+}$ at low resolution
$(\mathrm{R}=\sim 300)$. The instrumental parameters were optimized to obtain the stable signal intensity for ${ }^{11} \mathrm{~B}$ while keeping the $\mathrm{CeO}^{+} / \mathrm{Ce}^{+}$and $\mathrm{Ce}^{2+} / \mathrm{Ce}^{+}$ratios below $2 \%$. Two different combinations of cones were used, including an $\mathrm{X}$ skimmer cone + standard sample cone and an $\mathrm{H}$ skimmer cone + standard sample cone. The main operating conditions are listed in Table I.

Prior to sample analysis, the instrument was purged with ultrapure water for approximately one hour and then washed with 5\% (w/w) ammonia solution for approximately one hour to clear any trace elements from the previous sample and to change the media to alkaline.

\section{Reagents and Standard Solutions}

The ultrapure water (resistivity, 18.2 $\mathrm{M} \Omega / \mathrm{cm}$ ) used throughout the experiments, was obtained from a Milli-Q ${ }^{\circledR}$ water purification system (Millipore Corporation, USA). Concentrated $\mathrm{HNO}_{3}$ and $\mathrm{HF}$ (GR grade, SCR, Shanghai, P.R. China) were further distilled using a DST-1000 acid purification system (Savillex, Eden Prairie, USA). Chromatographic grade ammonia reagent (Aladdin, Shanghai, P.R. China) was used. The $1000 \mathrm{mg} \mathrm{mL}^{-1}$ stock solutions of single elements ( $\mathrm{Li}, \mathrm{Be}, \mathrm{B}$, $\mathrm{Na}, \mathrm{Al}, \mathrm{Cu}, \mathrm{Rb}, \mathrm{Y}, \mathrm{Rh}, \mathrm{In}, \mathrm{Te}, \mathrm{Ce}$, $\mathrm{Hf}, \mathrm{Pb}$, and $\mathrm{U}$ ) were purchased from the National Center for Analysis and Testing of Steel Materials, Beijing, P.R. China. The ammonia solutions $(1 \%, 3 \%, 5 \%$, and $7 \%$ w/w) were prepared by directly diluting the ammonia reagent with ultrapure water. Calibration was made using standard solutions of $B$ $\left(0,5,10,15\right.$, and $\left.20 \mathrm{ng} \mathrm{mL}^{-1}\right)$ with $5 \%(w / w)$ ammonia. We tested three internal standard elements (Y, $\mathrm{Rh}$, and In) in the ammonia matrix. The calibration blank and a series of working standards of B contained $1 \mathrm{ng} \mathrm{mL} L^{-1} \mathrm{Y}, \mathrm{Rh}$, and In. 
TABLE I

Operating Parameters for ICP-MS

RF power
Cooling gas flow rate
Auxiliary gas flow rate
Sample gas flow rate
Sample cone
Skimmer cone
Spray chamber temperature
Nebulizer
Mass resolution
Mass window
Sample time
Samples per peak
Integration window
Integration type
Scan type
Detection system
Runs
Passes

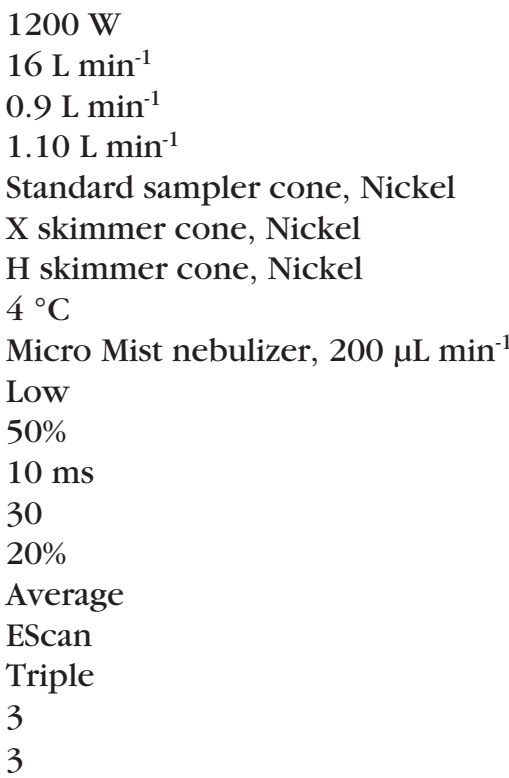

Using Class 100 clean laboratory conditions, the high-density polyethylene bottles and tubes were cleaned in 5\% (w/w) $\mathrm{HNO}_{3}$ for 24 hours and rinsed 3 times with ultrapure water before use. Great care was taken to prevent B contamination.

\section{Reference Materials}

To investigate the accuracy and precision of the proposed method, a series of international geological reference materials, including soils, sediments, shales, basalts, an andesite and granites were analyzed. Sixtyone geological reference materials were obtained from the United States Geological Survey (AGV-2, BCR-2, BHVO-2, BIR-1a, and SCO-1) and the Institute of Geophysical and Geochemical Exploration. Detailed sample information is listed in Table II.

\section{Sample Digestion Procedure}

Approximately $50 \mathrm{mg}$ of sample powder was weighed and soaked with $1 \mathrm{~mL} \mathrm{HNO}_{3}$ and $1 \mathrm{~mL} \mathrm{HF}$ in a homemade PTFE-lined stainless- steel bomb. Subsequently, the bomb was heated in an electric oven at $190^{\circ} \mathrm{C}$. After cooling, the slurry was diluted with $5 \%(w / w)$ ammonia solution to a final weight of $50 \mathrm{~g}$ and stored in polyethylene bottles. Then, $1 \mathrm{~mL}$ of supernatant solution was transferred to a polyethylene tube and $10 \mu \mathrm{L}$ of $1 \mu \mathrm{g}$ $\mathrm{mL}^{-1} \mathrm{Y}, \mathrm{Rh}$, and In standard solution were added to the sample solution. A reagent blank solution was simultaneously prepared for each group in the same way.

\section{RESULTS AND DISCUSSION}

\section{Effect of Digestion Time}

It is clear that decomposition of the samples is controlled by the synergistic effect of temperature and time. Due to the limitations of the physical and chemical properties of the PTFE-lined stainless-steel bomb and for the sake of efficiency, the digestion temperature of $190{ }^{\circ} \mathrm{C}$ is usually used in routine geological sample analysis (16). Figure 1 summarizes the effect of digestion time on the recovery of $B$ in three differ- ent types of geological materials (soil, GSS-7; sediment, GSD-18; rock, GSR-2) at $190{ }^{\circ} \mathrm{C}$. It can be seen from Figure 1 that $\mathrm{B}$ in these three geological materials was completely recovered at all given digestion times (0.5-30 hours). For the complete recovery of B in GSS-7, GSD-18, and GSR-2, the digestion time required only 30 minutes, which is approximately 144 times faster than a conventional mannitoladded HF digestion (28).

\section{Suppression of Ammonia Matrix Effect}

In ICP-MS, matrix effects are usually known to cause signal suppression with an increase in matrix concentrations. To the best of our knowledge, the effect of the ammonia matrix on the B signal in ICP-MS was never studied or reported. Figure 2 illustrates the ${ }^{11} \mathrm{~B}$ signal intensity as a function of nebulizer gas flow rate in $1 \%, 3 \%, 5 \%$, and $7 \%$ (w/w) ammonia solutions. Clearly, the optimum sample gas flow rate (corresponding to the maximum signal intensity of B) shifted to a lower gas flow rate when the ammonia concentration was increased from $1 \%$ to $7 \%$. The maximum signal intensity of ${ }^{11} \mathrm{~B}$ also gradually decreased with an increase in ammonia concentration. Generally, the suppression of the maximum signal intensity for ${ }^{11} \mathrm{~B}$ by the increase in ammonia concentration became more significant at higher nebulizer gas flow rates $\left(>1.12 \mathrm{~L} \mathrm{~min}^{-1}\right)$. These phenomena may be attributed to the local cooling effect of ammonium in the central channel of the plasma so that the aerosol particles are less effectively converted to atomic ions. It can be seen in Figure 2 that the B signal intensity was not affected by the change in ammonia concentration from $1 \%$ to $7 \%$ at nebulizer gas flow rates of 1.06-1.12 $\mathrm{L} \mathrm{min}^{-1}$. It seems that the ammonia matrix effect on B can be overcome by using a low sample gas flow rate of 
TABLE II

Experimental and Reference Values

in 61 Geological Reference Materials

\begin{tabular}{|c|c|c|c|c|c|}
\hline Materials & $\begin{array}{c}\text { Abbre- } \\
\text { viation }\end{array}$ & Sample Type & $\begin{array}{l}\text { ICP-MS } \\
\left(\mu \mathrm{g} \mathrm{g}^{-1}\right)\end{array}$ & $\begin{array}{r}\mathrm{Re} \\
(\mu \mathrm{g}\end{array}$ & $\left.\mathrm{g}^{-1}\right)$ \\
\hline GBW07401 & GSS-1 & Podzolic soil & $45.0 \pm 2.4$ & 50 & \pm 3 \\
\hline GBW07402 & GSS-2 & Soil & $35.8 \pm 0.3$ & 36 & \pm 3 \\
\hline GBW07403 & GSS-3 & Soil & $23.3 \pm 0.4$ & 23 & \pm 3 \\
\hline GBW07404 & GSS-4 & Soil & $97.3 \pm 3.7$ & 97 & \pm 9 \\
\hline GBW07405 & GSS-5 & Soil & $69.8 \pm 5.1$ & 53 & \pm 6 \\
\hline GBW07406 & GSS-6 & Soil & $68.4 \pm 3.6$ & 57 & \pm 5 \\
\hline GBW07407 & GSS-7 & Laterite & $10.0 \pm 0.3$ & 10 & \\
\hline GBW07408 & GSS-8 & Loess & $64.6 \pm 1.0$ & 54 & \pm 4 \\
\hline GBW07423 & GSS-9 & Sediment & $53.6 \pm 0.7$ & 52 & \pm 4 \\
\hline GBW07424 & GSS-10 & soil & $34.8 \pm 0.5$ & 35 & $\pm 3^{\mathrm{a}}$ \\
\hline GBW07425 & GSS-11 & Soil & $39.7 \pm 0.5$ & 36 & $\pm 3^{\mathrm{a}}$ \\
\hline GBW07426 & GSS-12 & Soil & $48.0 \pm 1.2$ & 55 & $\pm 5^{\mathrm{a}}$ \\
\hline GBW07427 & GSS-13 & Soil & $50.5 \pm 0.8$ & 53 & $\pm 3^{\mathrm{a}}$ \\
\hline GBW07428 & GSS-14 & Soil & $44.6 \pm 0.8$ & 46 & $\pm 3^{\mathrm{a}}$ \\
\hline GBW07429 & GSS-15 & Soil & $58.4 \pm 1.0$ & 63 & $\pm 2^{\mathrm{a}}$ \\
\hline GBW07430 & GSS-16 & Soil & $61.7 \pm 1.1$ & 63 & $\pm 4^{\mathrm{a}}$ \\
\hline GBW07446 & GSS-17 & Sandy soil & $20.9 \pm 0.4$ & 24 & \pm 3 \\
\hline GBW07447 & GSS-18 & Saline-alkali soil & $67.4 \pm 0.9$ & 62 & \pm 7 \\
\hline GBW07448 & GSS-19 & Soil & $50.2 \pm 1.2$ & 51 & \pm 4 \\
\hline GBW07449 & GSS-20 & Saline-alkali soil & $163 \pm 2$ & 143 & \pm 38 \\
\hline GBW07450 & GSS-21 & Soil & $50.8 \pm 2.9$ & 48 & \pm 6 \\
\hline GBW07451 & GSS-22 & Tidal flat sediment & $50.4 \pm 1.6$ & 52 & \pm 7 \\
\hline GBW07452 & GSS-23 & Tidal flat sediment & $76.5 \pm 3.2$ & 77 & \pm 8 \\
\hline GBW07453 & GSS-24 & Tidal flat sediment & $81.6 \pm 1.2$ & 83 & \pm 7 \\
\hline GBW07454 & GSS-25 & Soil & $57.2 \pm 0.6$ & 54 & \pm 6 \\
\hline GBW07455 & GSS-26 & Sediments & $54.7 \pm 1.1$ & 52 & \pm 8 \\
\hline GBW07456 & GSS-27 & Sediments & $67.7 \pm 1.4$ & 64 & \pm 7 \\
\hline GBW07457 & GSS-28 & Sediments & $77.8 \pm 1.1$ & 80 & \pm 10 \\
\hline GBW07301 & GSD-1 & Stream sediments & $5.84 \pm 0.51$ & 4.6 & \pm 0.9 \\
\hline GBW07302 & GSD-2 & Stream sediments & $9.81 \pm 0.89$ & 10.8 & $8 \pm 2.5$ \\
\hline GBW07303a & GSD-3a & Stream sediments & $52.7 \pm 1.3$ & 57 & \pm 7 \\
\hline GBW07304 & GSD-4 & Sediments & $58.1 \pm 1.1$ & 52 & \pm 6 \\
\hline GBW07305 & GSD-5 & Stream sediments & $53.1 \pm 0.6$ & 51 & \pm 6 \\
\hline GBW07306 & GSD-6 & Stream sediments & $48.6 \pm 2.1$ & 50 & \pm 7 \\
\hline GBW07307a & GSD-7a & Stream sediments & $220 \pm 4$ & 195 & \pm 32 \\
\hline GBW07308a & GSD-8a & Stream sediments & $4.73 \pm 0.18$ & 5.3 & \pm 1.1 \\
\hline GBW07308 & GSD-8 & Stream sediments & $3.14 \pm 0.25$ & 3.6 & \pm 0.7 \\
\hline GBW07309 & GSD-9 & Stream sediments & $56.0 \pm 3.2$ & 54 & \pm 6 \\
\hline GBW07310 & GSD-10 & Stream sediments & $19.5 \pm 0.4$ & 26 & \pm 4 \\
\hline GBW07311 & GSD-11 & Stream sediments & $61.6 \pm 3.5$ & 68 & \pm 5 \\
\hline GBW07312 & GSD-12 & Stream sediments & $22.6 \pm 0.6$ & 24 & \pm 2 \\
\hline
\end{tabular}

cont'd next page
1.06-1.12 $\mathrm{L} \mathrm{min}^{-1}$. Taking into consideration both the ammonia matrix effect and the B signal intensities, the nebulizer gas flow rate for sample analysis was set at 1.10-1.12 $\mathrm{L}$ min $^{-1}$.

\section{Effects of Different Cone Com- binations on Signal Intensity}

Two different combinations of cones were used in this study, such as an $\mathrm{H}$ skimmer cone + standard sample cone and an $\mathrm{X}$ skimmer cone + standard sample cone. Both skimmer cones were made of nickel. However, their tip angles were different. The H skimmer cone has a cylindrical entrance and a trumpet-shaped exit, while the $\mathrm{X}$ skimmer cone has a completely trumpet-shaped form (14). As shown in Figure 3, a significant improvement in analytical sensitivity was observed for most of these investigated elements when using the $\mathrm{S}+\mathrm{X}$ cone combination compared to the $\mathrm{S}+\mathrm{H}$ cone combination. The enhancement factors are negatively correlated with the mass number of elements. The light mass elements (e.g., Li, Be, and B) have an enhancement factor of 7.0-8.2. The results show that the use of the $\mathrm{S}+\mathrm{X}$ cone combination is very beneficial for the determination of low content $B$ in the samples. The $\mathrm{X}$ skimmer cone with the trumpetshaped entrance provides more space for the ion beams to enter the skimmer orifice. This difference may partly explain the observed signal enhancement effects.

\section{Selection of Internal Standard Elements}

When using ICP-MS measurements, internal standard elements are usually used to correct signal drift and matrix effect $(9,30)$. The elements $\mathrm{Y}, \mathrm{Rh}$, and In are very stable in acid media and often used as internal standard elements during ICP-MS analysis. However, it is possible that these elements may not be a suitable internal standard ele- 


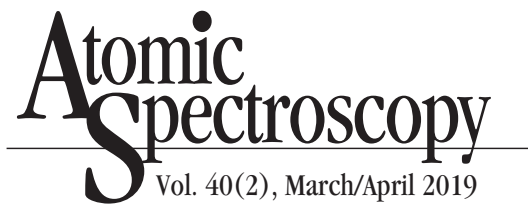

TABLE II (cont'd)

Experimental and Reference Values

in 61 Geological Reference Materials

\begin{tabular}{llllll}
\hline Materials & $\begin{array}{c}\text { Abbre- } \\
\text { viation }\end{array}$ & Sample Type & $\begin{array}{c}\text { ICP-MS } \\
\left(\mu \mathrm{g} \mathrm{g}^{-1}\right)\end{array}$ & $\begin{array}{c}\text { Ref. } \\
\left(\mu \mathrm{g} \mathrm{g}^{-1}\right)\end{array}$ \\
\hline GBW07317 & GSD-13 & Stream sediments & $5.25 \pm 0.45$ & $5.3 \pm 0.7$ \\
GBW07318 & GSD-14 & Stream sediments & $27.1 \pm 0.4$ & $27 \pm 4$ \\
GBW07358 & GSD-15 & Stream sediments & $52.8 \pm 1.1$ & 53 & \pm 7 \\
GBW07359 & GSD-16 & Stream sediments & $45.3 \pm 0.6$ & 48 & \pm 6 \\
GBW07360 & GSD-17 & Stream sediments & $61.3 \pm 0.3$ & 62 & \pm 6 \\
GBW07361 & GSD-18 & Stream sediments & $5.65 \pm 0.80$ & 5.5 & \pm 1.2 \\
GBW07362 & GSD-19 & Stream sediments & $16.0 \pm 0.9$ & 14 & \pm 3 \\
GBW07363 & GSD-20 & Stream sediments & $29.5 \pm 1.9$ & 28 & \pm 2 \\
GBW07364 & GSD-21 & Stream sediments & $31.4 \pm 4.4$ & $35 \pm 6$ \\
GBW07365 & GSD-22 & Stream sediments & $47.8 \pm 0.6$ & $46 \quad \pm 10$ \\
GBW07366 & GSD-23 & Stream sediments & $63.2 \pm 0.2$ & $70 \pm \pm 8$ \\
GBW07103 & GSR-1 & Granite & $22.9 \pm 0.6$ & 24 & \pm 3 \\
GBW07104 & GSR-2 & Andesite & $4.51 \pm 0.16$ & $4.7 \pm 0.8$ \\
GBW07105 & GSR-3 & Basalt & $1.50 \pm 0.37$ & $3.5 \pm 1$ \\
GBW07107 & GSR-5 & Shale & $174 \pm 5$ & $154 \pm 11$ \\
& AGV-2 & Andesite & $6.21 \pm 0.28$ & $6.45 \pm 0.52^{\mathrm{b}}$ \\
& BHVO-2 & Basalt & $2.41 \pm 0.16$ & $2.95 \pm 0.26^{\mathrm{b}}$ \\
& SCO-1 & Cody shale & $71.1 \pm 0.7$ & $72 \pm \pm 6^{\mathrm{b}}$ \\
& BIR-1a & Basalt & $0.211 \pm 0.182$ & $0.25^{\mathrm{b}}$ \\
& BCR-2 & Basalt & $3.42 \pm 0.31$ & $4.4^{\mathrm{b}}$ \\
\hline
\end{tabular}

ICP-MS = Experimental values determinated by ICP-MS

Ref. $=$ Reference values

Reference values (uncertainty: $1 \mathrm{~s}$ ) are taken from Wang et al. (40).

${ }^{a}$ Reference values (uncertainty: 95\% CL) are taken from Gu et al. (41).

${ }^{\mathrm{b}}$ Reference values (uncertainty: 95\% CL) are taken from Jochum et al. (42). ment in alkaline media. Figure 4 shows the variation in the signal intensities of the internal standard elements ( $1 \mathrm{ng} \mathrm{mL}^{-1} \mathrm{Y}, \mathrm{Rh}$, and $\left.\mathrm{In}\right)$ in 44 different sample solutions. The signal of Rh was very stable for all of these different sample solutions, while the signal of $Y$ was relatively stable in most of these different sample solutions. In contrast, the signal of In fluctuated drastically. This could be related to the formation of $\operatorname{In}(\mathrm{OH})_{3}$ in the aqueous ammonia solution (15). Therefore, $\mathrm{Rh}$ was a much more suitable internal standard element than $\mathrm{Y}$ and In for correcting the signal variation for B during ICP-MS analysis.

\section{Memory Effect}

The memory effect is one of the main obstacles for the accurate determination of $B$ in samples using ICP-MS analysis. In this study, three washing solutions $\left[\mathrm{H}_{2} \mathrm{O}, 5 \%(\mathrm{w} / \mathrm{w})\right.$ $\mathrm{HNO}_{3}$, and 5\% (w/w) ammonia] were tested. The time-resolved signal response for ${ }^{11} \mathrm{~B}$ was continuously monitored when the washing solution and the B standard solution were injected in turn. First, the signal was collected with the reagent blank within approximately 30 seconds, then the standard solu-

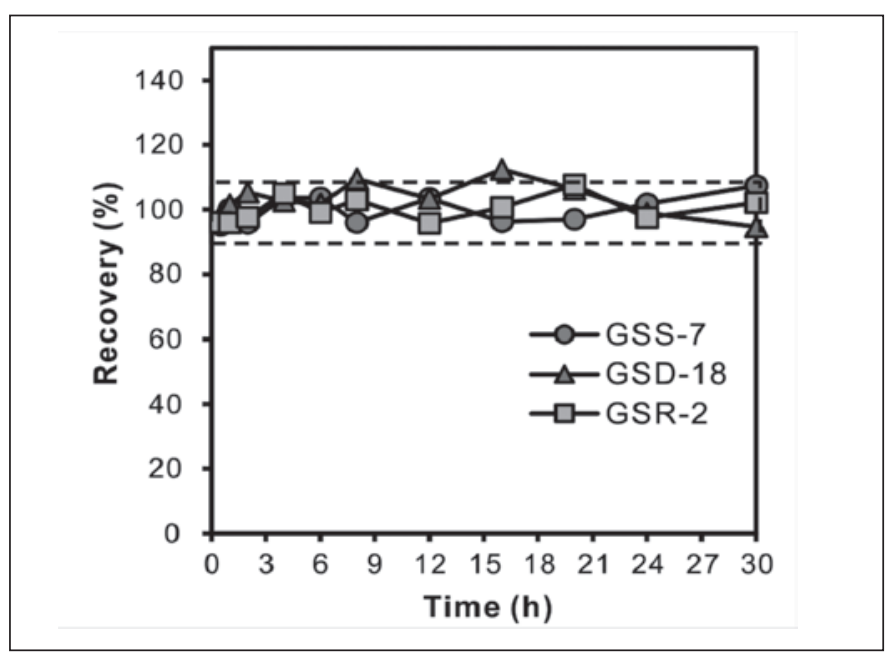

Fig. 1. Recovery of B in GSD-18, GSS-7, and GSR-2 as a function of digestion time at $190^{\circ} \mathrm{C}$.

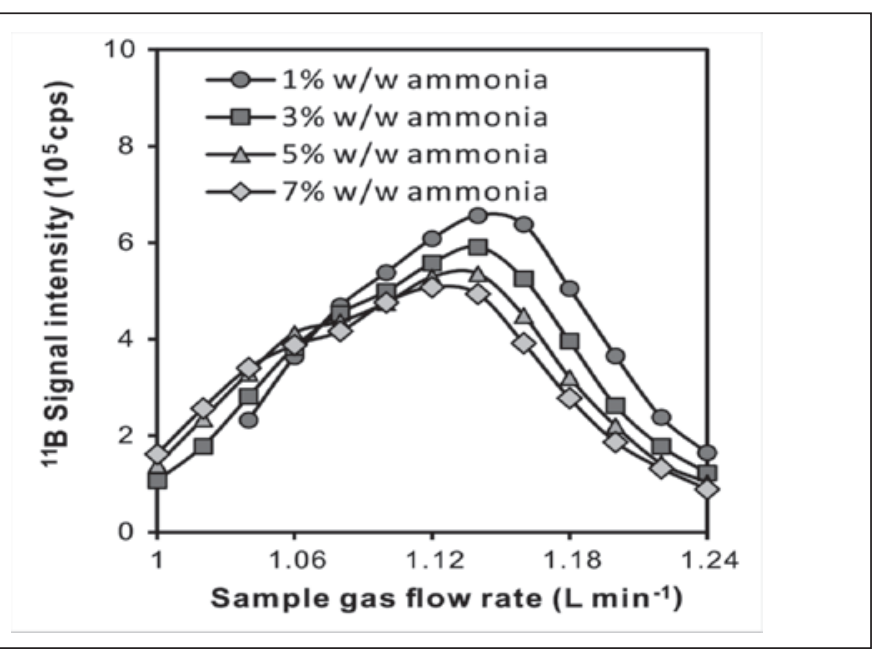

Fig. 2. Signal intensity of ${ }^{11} B$ as a function of sample gas flow rate in $1 \%, 3 \%, 5 \%$, and $7 \%(w / w)$ ammonia solutions. 


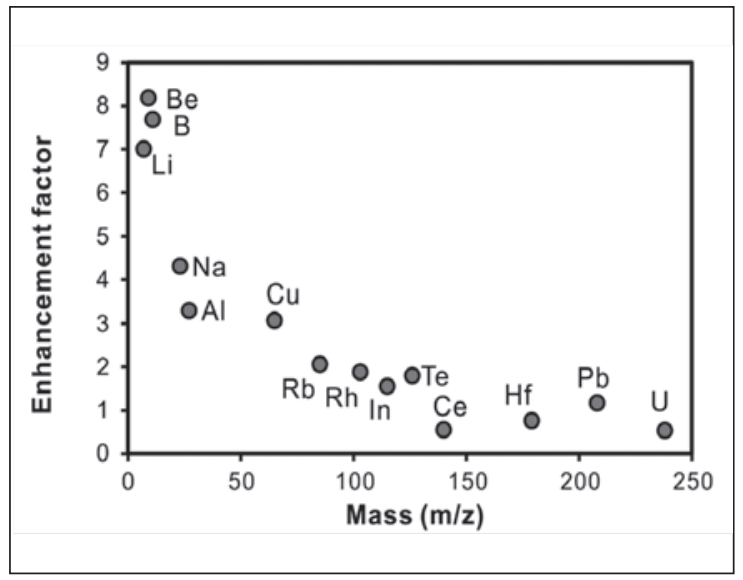

Fig. 3. Sensitivity enhancement factors for 14 elements using the $X$ skimmer cone + standard sampler cone compared to the standard arrangement (H skimmer cone + standard sample cone).

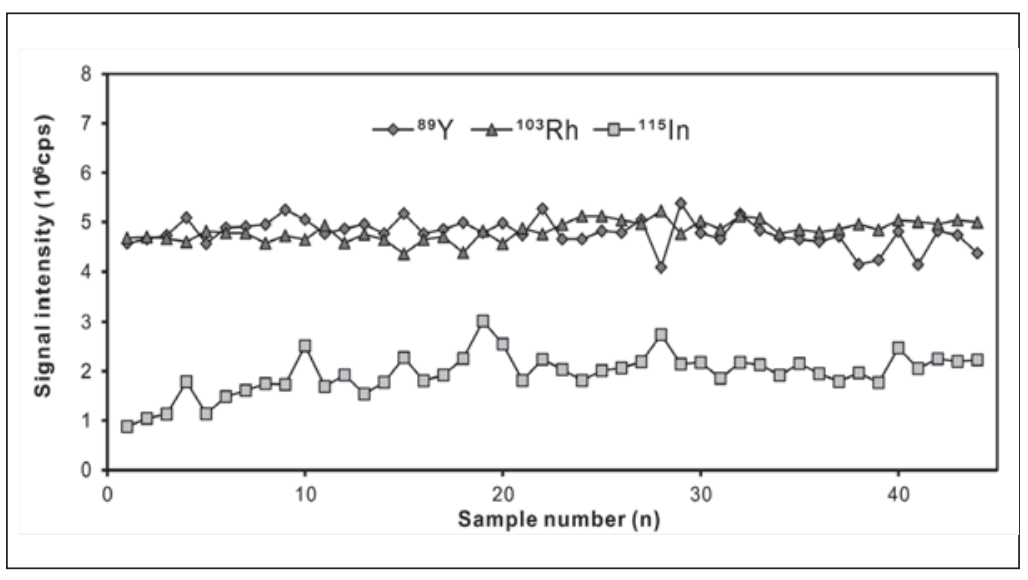

Fig. 4. Signal intensities of the internal standard elements (1 $n g m L^{-1} Y$, Rb and In) in 44 different sample solutions. tion was introduced for approximately 100 seconds, and finally the reagent blank was reintroduced as the washing solution for approximately 60 seconds (Figure 5 ). It is clear that the memory effect of $B$ observed in these three different washing solutions was different. The $\mathrm{H}_{2} \mathrm{O}$ and $5 \%$ (w/w) ammonia washing solutions are very effective for washout of the residual $\mathrm{B}$. The memory effect of B observed in these two washing solutions was negligible (Figure 5). However, over time, the background signals of ${ }^{11} \mathrm{~B}$ in $\mathrm{H}_{2} \mathrm{O}$ gradually increased from 55,000 to $115,000 \mathrm{cps}$. In contrast, the memory effect of $B$ is very significant using the $5 \%(\mathrm{w} / \mathrm{w})$ $\mathrm{HNO}_{3}$ solution. It required about 100 seconds for the B signal to drift from 600,000 to $200,000 \mathrm{cps}$. In addition, the background signal intensity of ${ }^{11} \mathrm{~B}$ was approximately 4 times that of $5 \%(w / w)$ ammonia solution. The ammonia washing solution together with the sample solution in the alkaline media also eliminated the corrosiveness of $\mathrm{HF}$ on the sample introduction system and the torch. Therefore, $5 \%(\mathrm{w} / \mathrm{w})$ ammonia solution was used as the washing solution in our experiments.

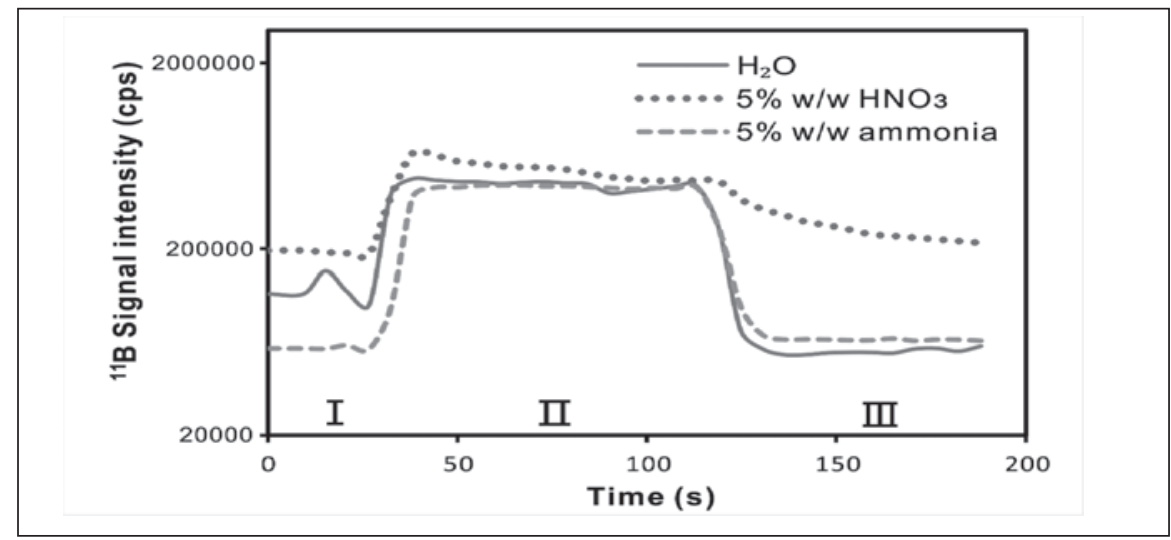

Fig. 5. Time-resolved signal intensity (cps) of ${ }^{11} \mathrm{~B}$ : (I) with reagent blanks [(1) $\mathrm{H}_{2} \mathrm{O}$, (2) $5 \%(w / w) \mathrm{HNO}_{3}$, and (3) 5\% (w/w) ammonia solution], (II) B standard solution, and (III) with reagent blanks as the washing solutions.

\section{Detection and Quantification Limits}

A reagent blank (5\% w/w ammonia) and a procedure blank were used to measure the limits of detection and quantitation, respectively. The limits of detection, calculated as three times the standard deviations of 10 measurements of ${ }^{11} \mathrm{~B}^{+}$ concentration was $0.0224 \mathrm{ng} \mathrm{g}^{-1}$. The limit of quantitation, which was calculated as 10 times the standard deviation of 10 measurements of ${ }^{11} \mathrm{~B}^{+}$concentration and then multiplied by the dilution factor used for sample preparation $(50 \mathrm{mg}$ of sample/50 g) was $0.0355 \mu \mathrm{g} \mathrm{g}^{-1}$.

\section{Analysis of Reference Materials}

Table II summarizes the results and reference values in 61 international soil, sediment, and rock reference materials. The reference values are taken from what has been published in GeoReM (http://georem.mpch-mainz. gwdg.de/) (40-42). Figure 6 compares the results for $B$ between our measured values and the reference values in these reference materials. It was clearly shown that the measured values were generally in good agreement with the reference values with correlation coefficients of 0.98 for $\mathrm{B}$. The results showed 


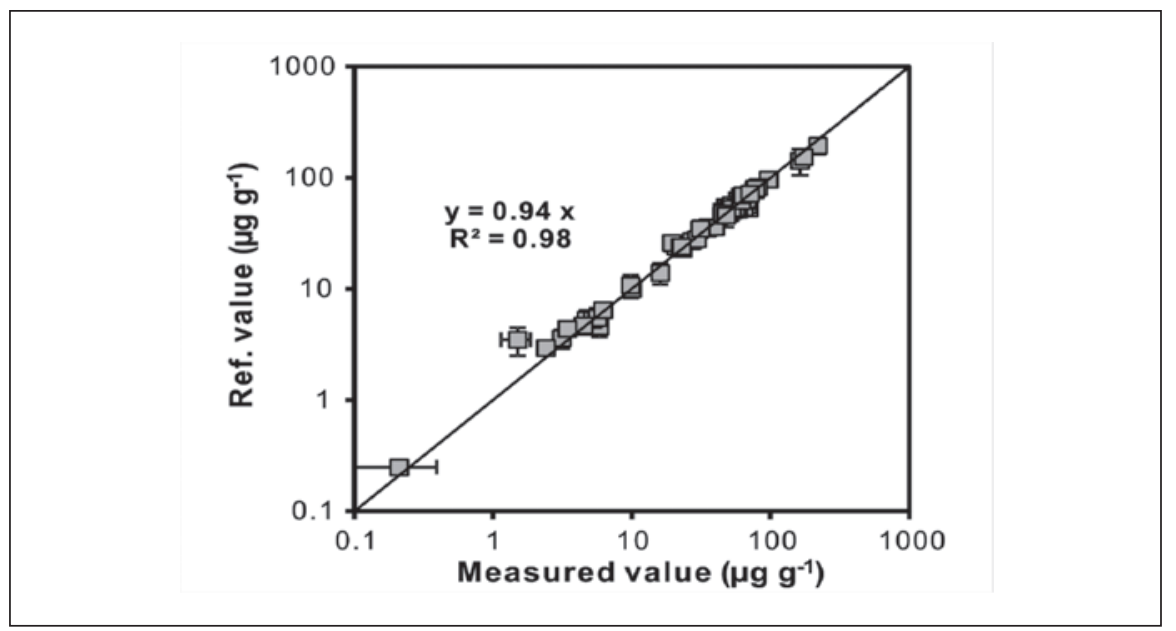

Fig. 6. Comparison of measured results and reference values for $B$ in 61 reference materials. Horizontal bars and vertical bars show one standard deviation for measured values and reference values, respectively.

agreement between our data obtained and the reference values were better than $10 \%$ for most of these soil, sediment, and rock materials, demonstrating the accuracy of the method (Table II). The obvious discrepancies for the basalt reference materials were as follows: GSR-3, BHVO-2, and BCR-2.

The discrepancies in the basalt reference materials are probably due to resistant minerals containing $B$ that are not being effectively attacked with a digestion time of only 30 minutes. In particular, the relative deviation of the $\mathrm{B}$ concentration in GSR-3 was 57\%. Therefore, we increased the digestion time from 0.5 hours to 24 hours at $190{ }^{\circ} \mathrm{C}$. These three newly measured values of $\mathrm{B}(1.28 \pm 0.05$, $1.38 \pm 0.40$, and $1.24 \pm 0.38 \mu \mathrm{g} \mathrm{g}^{-1}$, respectively) agreed with our previous measured values $(1.50 \pm 0.37$ $\left.\mu \mathrm{g} \mathrm{g}^{-1}\right)$ and were still significantly lower than the reference value $\left(3.5 \pm 1 \mu \mathrm{g} \mathrm{g}^{-1}\right)(40)$. It seems that a longer digestion time has no effect on the recovery of boron. Another reason for the discrepancies is that these reference values in GeoReM could be incorrect. Because most of the reference values are means of multiple analyses carried out by dif- ferent institutions using different methods, the values are not necessarily 'true'. We found that the determined values of $\mathrm{B}$ in BHVO-2 and BCR-2 (2.41 \pm 0.16 and $3.42 \pm$ $0.31 \mu \mathrm{g} \mathrm{g}^{-1}$, respectively) agreed better with recently published data, which were $2.8 \pm 0.3$ and $4.1 \pm 0.6$ $\mu \mathrm{g} \mathrm{g}^{-1}$, respectively (43).

\section{CONCLUSION}

A new method was developed for the direct determination of $B$ in soil, sediment, and rock samples by ICP-MS using a rapid acid digestion, followed by ammonia dilution. It took only 30 minutes of digestion time to completely recover B in $50 \mathrm{mg}$ of the soil (GSS-7), sediment (GSD-18), and rock (GSR-2) reference materials at a high digestion temperature of $190{ }^{\circ} \mathrm{C}$ and using $1 \mathrm{~mL} \mathrm{HNO}_{3}$ and $1 \mathrm{~mL} \mathrm{HF}$ in a PTFElined stainless-steel bomb. No loss of B was found in this study. The alkaline sample solution together with the ammonia washing solution not only eliminates the memory effect of $\mathrm{B}$, but also avoids the corrosiveness of $\mathrm{HF}$ on the ICP-MS sample introduction system. The presented method is considerably simpler than conventional methods and has great potential for the direct ICP-MS determination of boron in environmental and geological samples.

\section{ACKNOWLEDGMENT}

This research is supported by the National Natural Science Foundation of China (Grant 41403017) and the MOST Special Fund from the State Key Laboratory of Geological Processes and Mineral Resources.

Received January 8, 2019.

\section{REFERENCES}

1. P. J. White and P. H. Brown, Ann. Bot. 105(7), 1073 (2010).

2. Z. L. He, X. E. Yang and P. J. Stoffella, J. Trace Elem. Med. Biol. 19(2-3), 125 (2005).

3. H. R. Marschall and J. C. Schumacher, Nat. Geosci. 5(12), 862 (2012).

4. M. Scambelluri, T. Pettke, E. Rampone, M. Godard and E. Reusser, J. Petrol. 55(3), 459 (2014).

5. E. Cannaò, S. Agostini, M. Scambelluri, S. Tonarini and M. Godard, Geochim. Cosmochim. Acta 163, 80 (2015).

6. S. Tonarini, W. P. Leeman and G. Ferrara, J. Volcanol. Geotherm. Res. 110(1-2), 155 (2001).

7. J. Paquin, R. Altherr and T. Ludwig, Earth Planet. Sci. Lett. 218 (3-4), 507 (2004).

8. C. Özkul, E. Çiftçi, S. Tokel and M. Savas, J. Geochem. Explor. 173, 31 (2017).

9. R. N. Sah and P. H. Brown, Microchem. J. 56(3), 285 (1997).

10. A. Farhat, F. Ahmad and H. Arafat, Desalination 310, 9 (2013).

11. H. Kataoka, Y. Okamoto, S. Tsukahara, T. Fujiwara and K. Ito, Anal. Chim. Acta 610(2), 179 (2008).

12. S. Khan, M. Soylak, R. M. Alosmanov T. G. Kazi, and S. A. Sheikh, At. Spectrosc. 39(4), 158 (2018). 
13. Y. T. Li, W. Guo, Z. C. Hu, L. L. Jin, S. H. Hu, and Q. H. Guo, J. Agric. Food Chem. 67, 935 (2019).

14. L. Lin, Z. C. Hu, L. Yang, W. Zhang, Y. S. Liu, S. Gao and S. H. Hu, Chem. Geol. 386, 22 (2014).

15. T. He, J. Y. Xie, Z. C. Hu, T. Liu, W. Zhang, H. H. Chen, Y. S. Liu, K. Q. Zong and M. Li, Geostand. Geoanal. Res. 42(3), 309 (2018).

16. W. Zhang, Z. C. Hu, Y. S. Liu, L. Chen, H. H. Chen, M. Li, L. S. Zhao, S. H. Hu and S. Gao, Geostand. Geoanal. Res. 36(3), 271 (2012).

17. Z. C. Hu and S. Gao, Chem. Geol. 253(3-4), 205 (2008).

18. J. K. Aggarwal and M. R. Palmer, Analyst 120(5), 1301 (1995).

19. S. K. Aggarwal and C. F. You, Mass Spectrom. Rev. 36(4), 499 (2017)

20. X. Yan, S. Y. Jiang, H. Z. Wei, Y. Yan, H. P. Wu and W. Pu, Chin. J. Anal. Chem. 40(11), 1654 (2012).

21. M. Mihaljevič, O. Šebek, E. Lukešová and A. Bouzková, Fresenius J. Anal. Chem. 371(8), 1158 (2001).

22. A. Michel, J. Noireaux and M. Tharaud, Geostand. Geoanal. Res. 39(4), 489 (2015).

23. S. Misra, R. Owen, J. Kerr, M. Greaves and $\mathrm{H}$. Elderfield, Geochim. Cosmochim. Acta 140, 531 (2014).

24. I. Hlaváček and I. Hlaváčková, Microchim. Acta 99(3-6), 309 (1989).

25. T. Ishikawa and E. Nakamura Anal. Chem. 62(23), 2612 (1990).

26. E. Nakamura, T. Ishikawa, J. L. Birck and C. J. Allegre, Chem. Geol. 94(3), 193 (1992).

27. M. D'Orazio, Geostand. Newsl. 23(1), 21 (1999).

28. G. J. Wei, J. X. Wei, Y. Liu, T. Ke, Z. Y. Ren, J. L. Ma and Y. G. Xu, J. Anal. At. Spectrom. 28(4), 66 (2013).

29. Y. H. Liu, K. F. Huang and D. C. Lee, J. Anal. At. Spectrom. 33(5), 846 (2018)

30. K. Nagaishi and T. Ishikawa, Geochem. J. 43(2), 133 (2009)
31. J. Gaillardet, D. Lemarchand, C. Göpel and G. Manhès, Geostand. Newsl. 25(1), 67 (2001).

32. G. Menard, I. Vlastélic, D. A. Ionov, E. F. Rose-Koga, J. L. Piro and C. Pin, Chem. Geol. 354, 139 (2013).

33. A. Al-Ammar, R. K. Gupta and R. M. Barnes, Spectrochim. Acta, Part B 54(7), 1077 (1999).

34. D. H. Sun, R. L. Ma, C. W. McLeod, X. R. Wang and A. G. Cox, J. Anal. At. Spectrom. 15(3), 257 (2000).

35. A. S. Al-Ammar, R. K. Gupta and R. M. Barnes, Spectrochim. Acta, Part B, 55(6), 629 (2000).

36. S. Evans and U. Krähenbühl, J. Anal. At. Spectrom. 9(11), 1249 (1994).

37. M. Y. He, Z. D. Jin, C. G. Luo, L. Deng, J. Xiao and F. Zhang, J. Braz. Chem. Soc. 26(5), 949 (2015).

38. G. L. Foster, B. Hönisch, G. Paris, G. S. Dwyer, J. W. B. Rae, T. Elliott, J. Gaillardet, N. G. Hemming, P. Louvat and A. Vengosh, Chem. Geol. 358, 1 (2013).

39. J. Vogl, M. Rosner and W. Pritzkow, J. Anal. At. Spectrom. 26(4), 861 (2011).

40. Y. Wang, T. Gu, X. Wang, Y. Gao, K. P. Jochum and W. E. G. Müller, Practical handbook of reference materials for geoanalysis (2nd edition), Geological Publishing House (Beijing, P.R. China) (2013).

41. T. X. Gu, W. Bu, W. D. Yan, C. Y. Shi and M. C. Yan, Geostand. Newsl. 27(2), 197 (2003).

42. K. P. Jochum, U. Weis, B. Schwager, B. Stoll, S. A. Wilson, G. H. Haug, M. O. Andreae and J. Enzweiler, Geostand. Geoanal. Res. 40(3), 333 (2016).

43. L. Mori, A. Gómez-Tuena, Y. Cai and S. L. Goldstein, Chem. Geol. 244(3-4), 452 (2007). 